\title{
Silver nanoparticles as antibacterial agent aganist multidrug resistant Klbsiella pneumoni \\ M.G.Hassan ${ }^{1}$, S.A.Abo-ELmaaty ${ }^{1}$, S.A.Abd El-samee ${ }^{2}$, M.I.Ahmed ${ }^{1}$ and A.E.Mohammed ${ }^{1}$ \\ ${ }^{1}$ Botany and Microbiology, Dept., Faculty of Science, Benha Univ., Qalubiya, Egypt \\ ${ }^{2}$ Clinical Pathology, Dept., Faculty of Medicine, Benha Univ., Qalubiya, Egypt \\ E-Mail:manar.shama.090@gmail.com
}

\begin{abstract}
Antimicrobial-resistant bacteria-associated infections today pose a serious danger to human health, requiring the discovery of new antibacterial agents that are more effective than those already available. In this research, we utilised silver and chitosan nanoparticles to treat multidrug-resistant Klebsiella pneuomonia. Nanoparticles have been suggested as possible antimicrobial agents to fight infections.
\end{abstract}

Keywords: Silver nanoparticles, multidrug resistant bacteria MDR, Klebsiella pneumonia.

\section{Introduction}

In hospitals, Klebsiella pneumonia primarily affects patients with compromised immune systems, especially those in critical care units and emergency departments [1,2]. Historically, infections caused by the pathogen have been described as mild to moderate in severity; however, frequent exposure to antibiotics has lately increased the frequency of this severe bacterial illness. Antibiotic-resistant Klebsiella pneumonia strains have emerged as a consequence of the bacterium's development of resistance to several types of antibiotics $[3,4]$. Pneumonia, surgical site infections, bloodstream infections, and urinary tract infections are the most frequent hospital-acquired infections[5]. Klbsiella pneumonia is a gram-negative rod-shaped bacterium with a diameter of $0.3-1 \mathrm{~m}$ and a length of 0.6-6 m, found alone, in pairs, or in short chains [6]. Anaerobic bacteria such as Klebsiella produce large, pink pigment on Macconkey agar, indicating fermentation and acid production (the degree of mucoidness varies by strain and depends on the amount of carbohydrates in the culture medium) [7]. The amount of lactose and acid produced depends on the amount of carbohydrate present in the culture medium.

Nosocomial infections are a major cause for worry since many patients arrive at the hospital with weakened immune systems and are thus less equipped to fend off long-term infections [5]. There is an immediate need to find an effective alternative method since the bacteria has developed resistance to antibiotics. The antibacterial property of silver and its compounds has been known for a long time, and silver has been utilised to prevent and treat many diseases ever since $[9,10]$.

Many biological applications have demonstrated that silver nanoparticles have a great promise in silver research[11]. AgNPs have the ability to interact with bacteria's cellular apparatus. According to previous research, AgNPs have the potential to harm cellular components and membranes, resulting in structural alterations that make bacteria easier to pass through. The use of biological sources to synthesise nanoparticles is growing in popularity
[13, 14]. Silver has long been known for its antibacterial properties, dating back to antiquity. Due to advancements in antibiotics, silver's antibacterial use has decreased in medicine. Nanoscale size manipulation increases the antimicrobial properties of silver. Silver nanoparticles have emerged as antibacterial agents due to their high surface-area-tovolume ratio and unique chemical and physical characteristics due to their shift in physiochemical properties [17]. The bactericidal activity of silver nanoparticles in the $10-100 \mathrm{~nm}$ size range was shown against both Gram-positive and Gramnegative bacteria more than a few scientists have looked into the bactericidal activity of silver nanoparticles against pathogenic MDR and multidrug-susceptible bacterial strains. They've found the particles to be effective against MDR bacteria like Klebsiella pneumonia, CarbapenemesP. aeruginosa, and ampicillin-resistant organisms like erythromycin-resistant Escherichia coli Mycoplasma pneumoniae (MRSA), Streptococcus pyogenes (SP), and Staphylococcus aureus (VRSA) (VRSA). To compare with conventional metal nanoparticles, the silver nanoparticles show significant physicochemical characteristics, such as $\mathrm{pH}$-dependent partitioning to solid and liquid particulate matter and biological activities.

Due to their high surface-to-volume ratio and unique chemical and physical characteristics, silver nanoparticles have been used as antibacterial agents since antiquity [14, 17]. Antibiotic-resistant bacteria can be killed using silver nanoparticles since they are efficient bactericidal agents against a wide range of bacteria [19]. Aspergillus, Candida, and Saccharomyces are all prevalent fungi that this fastacting fungicide targets. Viral replication may be inhibited by silver nanoparticles with a diameter of 5-20nm. Besides altering proteinase expression, which is essential for inflammatory and repair processes, these may also decrease tumour necrosis factor (TNF) and cause death in inflammatory cells [22]. [23, 24] Furthermore, silver nanoparticles are in charge of wound healing cytokine regulation and biofilm inhibition [23]. 
A deacetylation process transforms chitin into chitosan, one of the most extensively used biopolymers. Since chitosan nanoparticles (CNPs) are nontoxic, nonimmunogenic, and may enable regulated drug release, they have piqued researchers' attention [24]. CNPs may increase the bioavailability of the medication they are connected to, as well as the drug's half-life and site of action targeting. For topical and systemic antimicrobial treatments, CNPs are the appropriate drug carrier of choice because of these characteristics [25]. This polymer is derived from the second most common natural compound after cellulose, chitin, which is a linear copolymer of (1-4)-linked 2,acetamido-2, deoxybeta,Dglucopyranose and 2, amino-2, deoxy-3,Dglucopyranose produced by deacetylation of its parent polymer We know that CS kills bacteria because of an electrostatic interaction between CS' $\mathrm{NH} 3+$ groups and phosphoryl groups in the membranes' phospholipid components and lipopolysaccharides (a kind of sugar). The permeability of pores increases, and the bacterial cell wall is disrupted as a result $[27,28]$.

\section{Material and methods}

\subsection{Bacterial strains and growing cultures}

Klebsiella pneumoniae was the first bacterium to be dubbed Gram-negative. All of the microorganisms used in this study were acquired from the microbiology department at Benha University Hospital's Faculty of Medicine. Isolates were purified on nutrient agar at $4^{\circ} \mathrm{C}$ using only bacteria that had been maintained in the proper conditions. Two times in nutrient broth, followed by plating on nutrient agar plates and picking up and processing an isolated colony, bacteria were subcultured before usage.

Vitek 2 Confirmation of Isolated Klebsiella pneumoniae Bacteria

Purity was ensured by incubation at $37^{\circ} \mathrm{C}$ for 24 hours to get single colonies after bacterial colonies were isolated on culture medium. Isolates were identified using a Vitek2 compact auto analyzer system at the Microbiology lab at Benha University's school of medicine [29].].

\section{The sensitivity of antibiotics}

using the disc diffusion method It was done using the Kirby-Bauer method [30], which included inoculating 1 millilitre of nutritional broth with standard concentrations of chosen bacteria (108 $\mathrm{cfu} / \mathrm{ml}$ ), cooling it down to $45^{\circ} \mathrm{C}$, and then pouring it on nutritional broth plates, which were then solidified. Then there are antibiotic discs. Table (1) contains standard concentrations of sixteen antibiotics that were administered to the plates' surface. For 24 hours, the plates were incubated at $37^{\circ} \mathrm{C}$ under under supervision. Assured and compared widths of inhibitory zone surrounding disc with standard antibiogram according to [31], findings were interpreted and classified as sensitive, moderate sensitive and resistant.

Silver and chitosan nanoparticle synthesis

The chemical reduction technique used by [32, 33] produced silver nanoparticles. As a precursor for Ag1+ ions, scientists used a solution of AgNO3. Borochloride served as a moderate reducer while PVP stabilised the sample. A gradual graying-out of the solution's hue, indicating the formation of silver nanoparticles from the silver ion, showed the reduction process had begun.

The inotropic gelatin method was used to make chitosan nanoparticles [34]. The addition of a tripolyphosphate (TTP) aqueous solution to a chitosan solution produced blank nanoparticles.

\subsection{Antimicrobial activity of nanoparticles is assessed using susceptibility assays.}

Different quantities of Nano silver and Nano chitosan were obtained from a specialist business by diluting distilled water $(1,0.5,0.25$ and $0.125 \mathrm{mg})$. The experiments were carried out on Muller Hinton agar using the disc diffusion technique. As part of this experiment, we employed various doses of nanoparticles on a sterilised paper disc $(0.5 \mathrm{~cm})$. When bacteria were grown overnight on Muller Hinton agar plates, sterilised discs were placed on top and the plates were incubated at $37 \mathrm{oC}$ for 24 hours. The inhibition zone was then measured to assess antimicrobial activity [35].

\section{Results and discussion}

Five Klebsiella pneumia isolates (kpn01, kpn02, $\mathrm{kpn03}$, kpn04, and kpn05) were recovered from sputum and blood specimens at the microbiology laboratory at Benha University Hospital. Nutrient agar medium was used to develop the isolates, which were then purified. Vitek2 was used to identify these isolates.

Testing for antibiotic resistance

The antibiotic sensitivity of the chosen isolates was examined. The disc diffusion technique was used to test the sensitivity of the five isolates to a total of sixteen different antibiotics. $S$ is for sensitive, I is for intermediate, and $\mathrm{R}$ is for resistant, as shown in Table (1).

Most of the isolates are resistant to antibiotics which made the researches to find a new alternative technique like nanoparticles as antibacterial agent.

Susceptibility of bacterial isolates to nanoparticles

The antimicrobial activity of different concentrations of chitosan nanoparticles against five isolates of Klbsiella pneumonia showed no antibacterial activity of all chitosan nanoparticles concentrations against the bacteria and this observed in Table (2). 
Table (1) Antibiotics Sensitivity test of the isolated klebsiella pneumonia bacteria.

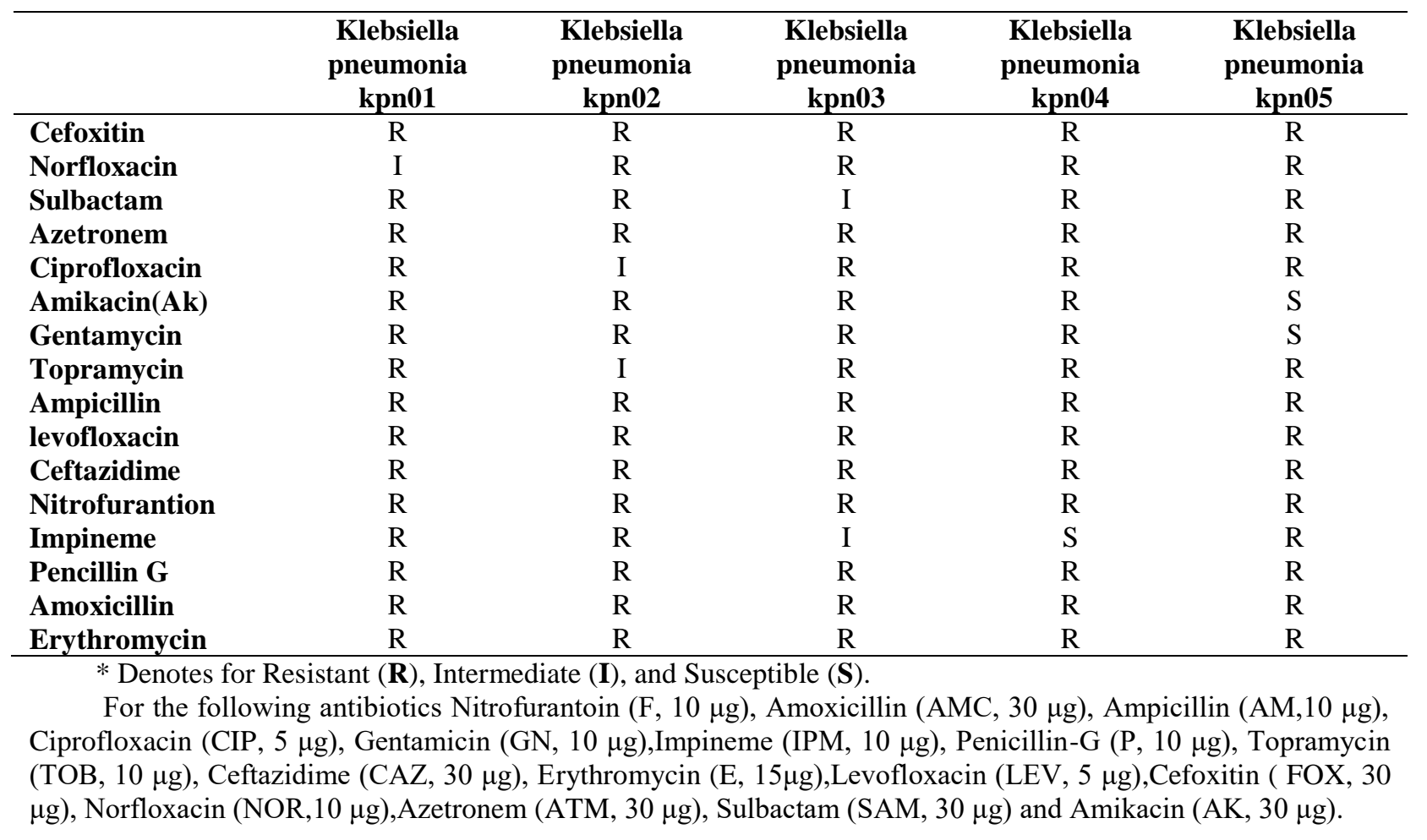

Table (2) Antibacterial activity of different Chitosan nanoparticles concentrations against five isolates of Klebsiella pneumonia bacteria.

\begin{tabular}{lcccc}
\hline Bacteria & \multicolumn{4}{c}{$\begin{array}{c}\text { Chitosan concentrations } \\
\text { (Diametre of inhibition zone(mm) Original } \\
\text { dimetere 5mm }\end{array}$} \\
& 0.125 & 0.25 & 0.5 & 1.0 \\
\hline Klebsiella pneumonia kpn01 & 5.0 & 5.0 & 5.0 & 5.0 \\
Klebsiella pneumonia kpn02 & 5.0 & 5.0 & 5.0 & 5.0 \\
Klebsiella pneumonia kpn03 & 5.0 & 5.0 & 5.0 & 5.0 \\
Klebsiella pneumonia kpn04 & 5.0 & 5.0 & 5.0 & 5.0 \\
Klebsiella pneumonia kpn05 & 5.0 & 5.0 & 5.0 & 5.0 \\
\hline
\end{tabular}

Table (3) Antibacterial activity of different Silver nanoparticles concentrations against five isolates of Klebsiella pneumonia bacteria.

\begin{tabular}{lcccc}
\hline Bacteria & \multicolumn{4}{c}{ Silver concentrations } \\
& (Diametre of & inhibition zone(mm) & Original & dimetere 5mm \\
& 0.125 & 0.25 & 0.5 & 1.0 \\
\hline Klebsiella pneumonia kpn01 & 5.0 & 5.0 & 10.0 & 12.0 \\
Klebsiella pneumonia kpn02 & 5.0 & 10.0 & 11.0 & 13.0 \\
Klebsiella pneumonia kpn03 & 10.0 & 12.0 & 13.0 & 14.0 \\
Klebsiella pneumonia kpn04 & 5.0 & 5.0 & 5.0 & 5.0 \\
Klebsiella pneumonia kpn05 & 5.0 & 12.0 & 13.0 & 14.0 \\
\hline
\end{tabular}

Table shows the antibacterial activity of various silver nanoparticle concentrations against five Klebsiella pneumonia isolates (3). This table shows that the highest concentrations of antibacterial diffrenet silver nanoparticles against bacterial isolates are effective, so we recommend using AgNps as an antibacterial agent. This is in line with the findings of [12], which suggest that silver nanoparticles disrupt cell function by attaching to the cell membrane's surface, penetrating bacteria, and releasing silver ions afterward.

\section{Conclusion}

This study describes the isolation of five isolates of pathogenic bacteria Klebsiella pneumonia from 
benha university hospital these bacteria is multi drug resistant because overuse of antibiotics so it was necessary to discover a new approaches technique to treat these pathogenic bacteria .so we recommend using silver nanoparticles as antibacterial agent.

\section{Reference}

[1] M.Souli, I.Galani, A.Antoniadou, E.Papadomichelakis, G. Poulakou, T. Panagea, An outbreak of infection due to beta-Lactamase Klebsiella pneumonia carbapenemase-2 producing $\mathrm{K}$. pneumoniae in a Greek university hospital: molecular characterization, epidemiology, and outcomes. Clin Infect Dis.vol.50,pp.364-73,2010.

[2] HC.Maltezou, Metallo-b-lactamases in gramnegative bacteria: introducing the era of panresistance. Int $\mathrm{J}$ Antimicrob Agents.vol.33,pp.405-7,2009.

[3] Y.Luo, J.Yang, Y.Zhang, L.Ye, L.Wang, L.Guo, Prevalence of beta-lactamases and 16S rRNA methylase genes amongst clinical Klebsiella pneumonia isolates carrying plasmid-mediated quinolone resistance determinants. Int J Antimicrob.vol.37,pp.3525,2011 .

[4] IE. Elgorriaga, NP.Guggiana, YM.Dominguez, RG.Gonzalez, LJ. Mella MS and Labarca, Prevalence of plasmid-mediated quinolone resistance determinant aac $\left(6^{\prime}\right)$-Ib-cr among ESBL producing enterobacteria isolates from Chilean hospitals. Enferm Infec Microbiol Clin.vol.30,pp.466-8,2012.

[5] R.Gaynes, J.Edwards, Surveillance Overview of Nosocomial Infections Caused by GramNegative Bacilli. Clinical Infectious Diseases.vol.41,pp. 848- 854,2005.

[6] L.Wang, H.Gu, X. Lu, A rapid low-cost realtime pcr for the detection of Klebsiella pneumoniae carbapenemase genes. Annals of Clin. Microbiol. and Antimicrob.vol.11(9),pp.1-6,2012.

[7] V.L.Yu, D.S.Hansen, W.C. Ko, Virulence characteristics of Klebsiella and clinical manifestations of K.pneumoniae bloodstream infections. Emerg Infect Dis.vol.13(7),pp.98693,2007.

[8] K.Todar, The Mechanism of Bacterial Pathogenicity “Klebsiella'. Todar's Textbook of Bacteriology. Wisconin-Madison Inc, U.S.A. ,2007.

[9] D.Jain, HK.Daima, S.Kachhwaha, SL. Kothari, Synthesis of plant-mediated silver nanoparticles using papaya fruit extract and evaluation of their antimicrobial activities.Digest J Nanomater Biostructures.vol.4,pp.55-763,2009.

[10]A. Singh, D.Jain, M.K. Upadhyay, N. Khandelwal, HN. Verma, Green synthesis of silver nanoparticles using Argemone mexicana leaf extract and evaluation of their antimicrobial activities. Digest J Nanomater Biostructures.vol.5,pp.483-9,2010.

[11] V.K.Sharma, R.A.Yngard, Y. Lin , Silver nanoparticles: green synthesis and their antimicrobial activities. Adv Colloid Interface Sci.vol.145,pp.83-96,2009.

[12] V. Lazar Quorum, sensing in biofilms: How to destroy the bacterial citadels or their cohesion/power? Anaerobe.vol.17,pp.2805,2011 .

[13] B.Nowack, HF. Krug, M.Height, 120 y of nanosilver history: implications for policy makers. Environ Sci Technol.vol.45,pp.117783,2017.

[14] J.R.Morones, J.L. Elechiguerra, A.Camacho, K.Holt, J.B. Kouri, J.T. Ramirez, The bactericidal effect of silver nanoparticles. Nanotechnology.vol.16,pp.2346-53,2005.

[15] J.J. Castellano, S.M.Shafii, F. Ko, G.Donate, T.E.Wright, R.J. Mannari, W.G.Payne, D.J.Smith, Comparative evaluation of silvercontaining antimicrobial dressings and drugs. Int Wound J .vol.4 ,pp.14-22,2007.

[16]X. Chen, H.J. Schluesener, Nano-silver: a nanoproduct in medical application. Toxicol Lett .vol.176,pp.1-12,2008.

[17] J.S.Kim, E.Kuk, K.N.Yu, J.H.Kim, S.J.Park, H.J.Lee, D.H.Jeong, M.H.Cho, Antimicrobial effects of silver nanoparticles. Nanomed Nanotechnol Biol Med .vol.3,pp.95-101,2007.

[18] C.N.Lok, C.M.Ho, R.Chen, Q.Y.He, W.Y.Yu, H.Sun, P.Kwong-Hang, T.J.Chiu, Proteomic analysis of the mode of antibacterial action of silver nanoparticles. J Proteome Res .vol.5,pp. 916-924,2006.

[19] S.L.Percival, P.G.Bowler, J.Dolman, Antimicrobial activity of silver-containing dressings on wound microorganisms using an in vitro biofilm model. Int Wound J.vol. 4,pp. 186-191,2007.

[20] R.W. Sun, R.Chen, N.P. Chung, C.M.Ho, C.L.Lin, C.M.Che, Silver nanoparticles fabricated in Hepes buffer exhibit cytoprotective activities toward HIV-1 infected cells. Chem Commun (Camb) .vol.40, pp.5059-5061,2005.

[21] H.Humberto, V.Lara, N.V.Ayala-Nunez, L.D.Carmen, T.Ixtepan, R.P.Cristina, Bactericidal effect ofsilver nanoparticles against multidrug-resistant bacteria.World J Microbiol Biotechnol .vol.26,pp. 615621,2010 .

[22] K.C.Bhol, J. Alroy, P.J.Schechter, Antiinflammatory effect of topical nanocrystalline silver cream on allergic contact dermatitis in a guinea pig model. Clin Exp Dermatol .vol.29, pp.282-287.2004. 
[23]J.Tian, K.K.Wong, C.M.Ho, C.N.Lok, W.Y.Yu, C.M.Che, J.F.Chiu, P.K.Tam, Topical delivery of silver nanoparticles promotes wound healing. Chem Med Chem .vol.2,pp.129-136,2007.

[24] A.Kumar, A.Vimal, A.Kumar, Why Chitosan? From properties to perspective of mucosal drug delivery. Int. J. Bio. Macromol.vol. 91,pp.615-622,2016..

[25] R.Cheung, T.Ng, J.Wong, W.Chan, Chitosan: an update on potential biomedical and pharmaceutical applications. Mar. Drugs .vol.13(8),pp.5156-5186,2015..

[26] S.Ahmed, S.Ikram , Chitosan based scaffolds and their applications in wound healing. Achiev Life Sci.vol.10,pp.27-7,2016.

[27] H. Liu, Y. Du, X. Wang, L.Sun, Chitosan kills bacteria through cell membrane damage. Int $\mathrm{J}$ Food Microbiol.vol.95,pp.147-55,2004..

[28] AM.Piras, G.Maisetta, S.Sandreschi, S.Esin, M.Gazzarri, Batoni G. (2014). Preparation, physical-chemical and biological characterization of chitosan nanoparticles loaded with lysozyme. Int J Bio Macromol.vol.67,pp.124-31,2014.

[29] Y.A.Abbas, G.F.Radhi, Rabid identification of Enterobacter spp isolated from hospitals in basrah provience by automated system (Vitek2compact).International Journal of science.vol.2 (2),pp.9,2016.

[30] A.W.Bauer, W.M.Kirby, J.C.Sherris, M.Turck, Antibiotic susceptibility testing by a standardized single disk method. Am.J. of clin. pathol.vol. 45(4),pp. 493-496,1966..

[31]CLSI, Performance Standards for Antimicrobial Susceptibility Testing. 28th ed. CLSI supplement M100. Wayne, PA ,2018.

[32] J.Turkevich, P. C. Stevenson, J.Hiller, Astudy of the nucleation and growth processes in the synthesis of colloidal gold. Discussion of the Faraday Society.vol. 11,pp. 55-75,1951.

[33]P.C.Lee, D.Meisel, Adsorpation and surfaceEnhanced Raman of Dyes on Silver and Gold Sols. Journal of Physical Chemistary.vol.86 (17),pp.3391- 3395,1982.

[34] T.Hasanin Mohamed, Production of WellDispersed Aqueous Cross-Linked ChitosanBased Nanomaterials as alternative Antimicrobial Approach Journal of Inorganic and Organometallic polymers and Materials .vol.28 (4),pp.1502-1510,2018.

[35]C.George, S.Kuriakose, B.Prakashkumar, T.Mathew, Synthesis, charactrisation and antibacterial applications of water-soluble silver nanoparticle-encapsulated $\quad \beta$ cyclodextrin supramolecular chemistry.vol. 22(9),pp.511-516,2010. 